\title{
Tree survival and maximum density of planted forests - Observations from South African spacing studies
}

Klaus v. Gadow ${ }^{1,2}$ and Heyns Kotze ${ }^{3^{*}}$

\begin{abstract}
Background: Among the most important aspects of risk and hazard studies relating to forest ecosystems are maximum forest density and density-dependent tree survival.

Methods: Long-term observations about the maximum density of unthinned Pinus patula and P. elliottii field plots based on the Correlated Curve Trend (CCT) spacing studies which were established almost 8 decades ago by O'Connor (Forest Research with Special Reference to Planting Distances and Thinning, 1935) in South Africa. Three specific approaches were introduced for analysing maximum density and tree survival, namely the 'limiting line', Nilson's sparsity and tree survival with the Weibull function.

Results: The main results are:

a) Maximum densities differ greatly among the two species grown on the same site and within the same species grown on different sites; it is possible to relate these differences to site index in both species.

b) The relationship between the quadratic mean diameter and the minimum average spacing of surviving trees (known as Nilson's Sparsity) appears to be surprisingly similar in both species.

c) An analysis of tree survival in response to different initial planting espacements shows that the Weibull survival function parameters can be estimated if the initial planting density is known. This result is presented for each of the eight large experiments used in this study.
\end{abstract}

Conclusions: This study contributes to a better understanding of tree survival and maximum density which are the key factors required for estimating risk and uncertainty. The risk of tree mortality is not constant, but varies with tree species, planting density, tree age and growing site. For estimating that risk, therefore, continuous long-term observation on different sites and with varying planting densities, as provided by the unthinned CCT series, are essential.

Keywords: Self-thinning; Mortality; CCT; Pinus patula; Pinus elliottii; South Africa; Nelder

\section{Background}

Risk and uncertainty, - these words have initiated ardent debates and extensive interdisciplinary studies. What is risk? The choice between harvesting a tree or leaving it to grow is always risky. If the tree is harvested now, there is a risk that its future value could increase beyond expectations. If not, there is a risk of having missed a chance. It is not possible to escape this dilemma that is

\footnotetext{
* Correspondence: heyns.kotze@mondigroup.co.za

${ }^{3}$ Mondi, South Africa Division, Hilton, South Africa

Full list of author information is available at the end of the article
}

inherent in every decision (Weiss 2001). Risk has been defined as "the probability and magnitude of an adverse effect" (Lowrance 1980). More specifically, it is an expected loss caused by a potential hazard that may occur in a given reference area at a specific time.

Obviously, there is a constant need to improve our ability to predict hazards. One that concerns forest ecosystems in particular, is density-dependent tree mortality which is also known as self-thinning (Yoda et al. 1963; Gingrich 1967; Drew and Flewelling 1979; Zeide 1987; Hynynen 1993; Luyssaert et al. 2008). Observations about the maximum density of a planted forest may be 
assessed in unthinned and sufficiently large field plots maintained over long periods of time. Ideally, the experiment should include planting densities ranging from very low to very high stocking. High planting densities demonstrate effects of self-thinning while low densities reveal how widely-spaced trees are capable of occupying available free growing space. The study sites should be observed throughout the life of the trees to eliminate age effects, and they should cover an area that will carry a sufficient number of surviving large trees at maturity. Such a design will provide information about the maximum density of a planted forest independent of tree age or average tree size. Accordingly, this contribution presents a study based on long-term observations of maximum density in unthinned Pinus patula, P. elliottii and Eucalyptus grandis field plots based on Correlated Curve Trend (CCT) spacing studies established by O'Connor (1935) in South Africa.

Maximum forest density may be one indicator of shifts in ecosystem response to changes in the climate (Grace et al. 2002; Greenberg et al. 2009). Observations about maximum forest density may thus provide a new powerful basis for environmental gradient analysis, for example in addressing the question: which are the site conditions that most affect the potential density of a forest ecosystem? Knowledge of maximum forest density, for example in the Tropics or in Boreal regions, will permit potential Biomass and Carbon Estimates and relate those estimates to observed values.

In addition, the ability to predict maximum forest density will enable foresters to quantify the reduction of biomass and the loss in carbon sequestration by timber harvesting. This will permit more accurate and comprehensive comparisons of alternative "paths" of forest management (Gadow 2013). Thus, there are good reasons for improving our ability to estimate the potential density of managed and unmanaged forest ecosystems.

Based on previous studies of long-term experiments in unmanaged forests growing at very high densities, we conclude that the problem of estimating potential density is not as trivial as it may appear. Accordingly, the objective of this contribution is to estimate the potential density of unthinned forests using a detailed and comprehensive dataset and specific modeling approaches, including individual tree survival functions. We want to investigate the effect of different growing sites on the maximum density of the same species and the maximum density of different species growing on the same site.

\section{Methods}

This section presents details about the CCT spacing trials and the observations that were used in this study, and the methods that were applied.

\section{The observations}

Direct assessment of the potential density, and of the development towards that elusive state, requires densely stocked unmanaged and sufficiently large field plots that are enumerated regularly during long observation periods. A rare example of such an elaborate experiment is the Correlated Curve Trend (CCT) spacing study established by O'Connor (1935) in South Africa. The CCT experiment is a classic spacing trial designed to predict yields from plantations of various species of pine and eucalyptus for a wide range of densities, varying between extremely dense (2965 stems per ha) and free growth (124 stems per ha). Additional file 1: Table S1 shows details of the eight experiments used in this paper, and a map with their locations in South Africa.

The original objective of the CCT study was to predict yields from plantations of various species of pine and eucalypt for a wide range of planting densities. Most of the experiments were established between 1936 and 1938 and several detailed descriptions of the CCT design were published during the past 70 years (see for example Craib 1939; Marsh 1957; O'Connor 1960; Burgers 1976; Van Laar 1982; Gadow 1987; Bredenkamp et al. 2000). Some relevant details of four spacing trials each for Pinus patula and P. elliotti are presented in Additional file 1: Table S1. The altitudes range from 53 m.a.s.l. (Kwambonambi) to 1400 m.a.s.l. (Nelshoogte), the mean annual temperatures from $15.9^{\circ} \mathrm{C}$ (Weza) to $21.8^{\circ} \mathrm{C}$ (Dukuduku) and the mean annual precipitation from $830 \mathrm{~mm}$ (Weza) to $1463 \mathrm{~mm}$ (MacMac).

Soil depths and geology were also assessed in each of the eight experiments. With a depth of $120-150 \mathrm{~cm}$ the soils are deep in all experiments. Humic soils on granite are encountered in the MacMac and Nelshoogte experiments, sandy soils in Dukuduku and Kwambonambi and red apedal dystrophic soils in Entabeni on basalt. The mean height of dominant trees at age 20 (SI20) is lowest for P. elliottii at Dukuduku $(17.0 \mathrm{~m})$ and highest for P. patula at MacMac $(24.3 \mathrm{~m})$. Further details are presented in Additional file 1: Table S1.

The typical CCT experiment consists of 18 plots, covering 0.081 ha each. Nine of the 18 plots were left unthinned, the other nine were subjected to various thinning regimes. The treatment details for plots 1-8, and a map of the CCT spacing study Nelshoogte, are presented in Additional file 2: Table S2.

The unthinned experiment, known as the Basic Series, provides information about the growth of unthinned stands for a wide of range of planting densities. In the other, known as the Thinned Series, the response to various thinning regimes may be assessed. Eight nominal stand densities, ranging from 124 to 2965 stems per hectare, were established in plots 1 to 8 of the basic 
series. In order to avoid suppression by competing herbaceous flora, all plots were initially planted at 2965 stems per hectare and then thinned 'in advance of competition' until the nominal stocking was achieved (for further details of the trial design refer to Bredenkamp 1984 and Gadow and Bredenkamp 1992, p. 55 et sqq.). In this study only the results from several basic series are used.

Data from the CCT experiments are suitable for analysing tree survival in response to forest density and tree age. Additional climate and soil data have become available more recently, allowing a more detailed analysis of environmental effects.

\section{Methods to describe maximum density}

This section introduces three specific approaches for analyzing maximum density and tree survival. We define the rate of survival as the ratio $\frac{N_{2}}{N_{1}}$ while mortality may be expressed by $\frac{N_{1}-N_{2}}{N_{1}}$.

\section{Limiting line}

Populations of trees growing at high densities are subject to density-dependent mortality or self-thinning. For a given average tree size there is a limit to the number of trees that may co-exist. The relationship between the average tree size (increasing over time) and the number of live trees per unit area (declining over time) may be described by means of a "limiting relationship" or "limiting line". A convenient model for estimating this relationship is the following:

$$
\mathrm{N}_{\max }=a_{0} \mathrm{D}^{a_{1}}
$$

where Nmax is the maximum number of surviving trees per ha, $D$ is the quadratic mean diameter $[\mathrm{cm}]$ and $a_{0}, a_{1}$ are empirical parameters which can be estimated from fully stocked, unthinned trials. Reineke (1933) plotted the number of trees per unit area of "fully stocked stands" over their average diameter and concluded that the $a_{1}$ parameter is a constant equal to -1.605 (Oliver and Larson 1996, pp 353-354; Zeide 2004).

\section{Nilson's sparsity}

In the case of a regular spatial distribution of the trees within a forest, the average distance between the trees (L) may be estimated by the square root of the number of $\mathrm{m}^{2}$ in a hectare divided by the number of trees per ha $(\mathrm{N})$ :

$$
\mathrm{L}=\frac{100}{\sqrt{N}}
$$

Nilson (2006) called this average distance between the trees "stand sparsity" and proposed to estimate the minimum distance among the survivors using the following relationship:

$$
\operatorname{Lmin}=a+b \cdot D
$$

Lmin is the stand sparsity (m), and D is the quadratic mean diameter $(\mathrm{cm})$ of the trees in a stand; $a$ and $b$ are empirical parameters. The two variables have the same dimension and the relationship is assumed to be linear. Nilson's sparsity is an alternative way of evaluating the limiting density of trees, and thus an alternative to the limiting line. We may use equations (2) and (3) to get:

$$
N_{\max }=\frac{10000}{(a+b \cdot D)^{2}}
$$

If this equation is fitted to the data, the results are almost identical to those obtained with equation (1a). In both $1 \mathrm{a}$ and $1 \mathrm{~b}$, the dependent and independent variables have different units ( $\mathrm{N}$ per ha and $\mathrm{cm}$ ).

\section{Tree survival}

Survival analysis is most often defined as a class of statistical methods for studying the occurrence and timing of events, such as death (e.g., Cox and Oakes 1984). Survival analysis investigates the distribution of the non-negative random variable $T$ which in our study describes the forest age (Staupendahl 2011; Staupendahl and Zucchini 2011). According to Klein and Moeschberger (1997, pp. 21), the pattern of $T$ can usually be characterised by several functions. The probability density function $f(t)$ describes the frequency distribution of the points in time, in which trees die. In the case of continuously measured time, it is defined by:

$$
f(t)=\lim _{\Delta t \rightarrow 0} \frac{P(t \leq T<t+\Delta t)}{\Delta t}, \quad \text { with } t \geq 0
$$

For small $\Delta t, f(t) \Delta t$ may be thought of as the approximate unconditional probability that tree death will occur at time $t$. The cumulative distribution function $F(t)$, as the integral of the density function, gives the probability that a death has occurred by time $t$ :

$$
F(t)=P(T \leq t)=\int_{0}^{t} f(x) d x
$$

The survival function $S(t)$ is the complement of $F(t)$ and gives the probability that a tree survives at least until time $t$ :

$$
S(t)=P(T>t)=1-F(t)
$$

Because of its flexibility and parameter parsimony, Dickel et al. (2010) selected the Weibull distribution (Weibull 1951). If $T$ is Weibull distributed with scale 
parameter $\mathrm{b}$ and shape parameter $\mathrm{c}$, the survival function is given by:

$$
S(t)=\exp \left[-\left(\frac{t}{b}\right)^{c}\right]
$$

with $t>0$. In this study, we will fit the survival function (Equation 7) to observed surviving $P$. patula and $P$. elliottii trees $\mathrm{n}$ years after planting and try to relate its parameters to the different planting espacements.

\section{Results}

Maximum density Limiting line and site index

The limiting line was fitted to the CCT experiments listed in Additional file 1: Table S1 and the parameter estimates for the eight datasets are listed in Additional file 3: Table S3. Not surprisingly, the value of $a_{1}$ deviates considerably from the constant -1.605 proposed by Reineke (1933). Previous studies have shown that the exponent may assume a wide range of values, depending on tree species and site conditions (Gadow 1986). The relationship between the intercept (coefficient $\mathrm{a}_{0}$ ) and the site index is shown in the graph on the right of Additional file 3: Table S3.

The value of the intercept, which is the most important indicator of maximum density, is increasing with increasing site index. This is apparent in both species. The relationships between site index and $\mathrm{a} 0$ are:

$$
\begin{aligned}
\text { Pinus elliottii }: \mathrm{a}_{0}= & -464924+64472 * \text { SI } 20 \\
& \times\left(\mathrm{R}^{2}=0.79, \mathrm{n}=4\right) \\
\text { Pinus patula }: \mathrm{a}_{0}= & -2542807+142609 * \text { SI20 } \\
& \times\left(\mathrm{R}^{2}=0.88, \mathrm{n}=4\right)
\end{aligned}
$$

The results of relationships (8), (9) are based on four experiments for each of the two species. The database is limited. Nevertheless, to our knowledge, this is the first time that an estimate of maximum density could be related to site index. The range of site indices (17-24 m and $20-24 \mathrm{~m}$ ) is relatively broad and covers a wide range of the growing sites where the two species are found in South Africa. The dramatic effect of the environment on the maximum density of the same species can be seen in Figure 1 which shows the limiting line fitted to Pinus elliottii MacMac using the 0.975 percentile data.

The limiting lines for the Pinus elliottii experiments in MacMac and Kwambonambi are also shown in Figure 1, with the log transformed variables. The lines are almost parallel and the difference between the intercepts in terms of maximum surviving trees for a given mean diameter is considerable. For example, for a quadratic mean dbh of $30 \mathrm{~cm}$ the maximum number of live trees is estimated at $\mathrm{N}_{\max }=781116.5 \cdot 30^{-2.09}=639$ per ha in
Kwambonambi and at $\mathrm{N}_{\max }=1063674.8 \cdot 30^{-2.04}=$ 1032 in MacMac. Kwambonambi supports only 67 percent of the MacMac maximum and the difference between the two sites, given a quadratic mean dbh of $30 \mathrm{~cm}$, is $1032-639=393 \mathrm{P}$. elliottii trees per ha. The growing conditions are very different. Considerably more trees are able to survive on the cool mountain site at MacMac than on the warm subtropical sandy site at Kwambonambi.

\section{Nilson's sparsity}

The parameters of Equation 3 can be estimated using data from fully stocked, unthinned trials, again using specific percentile values and the $\mathrm{R}$ library quantreg. The relations are presented in Figure 2 and the corresponding equations are:

$$
\text { Lmin }=0.4044+\mathrm{D} * 0.0870 \text { for all Pinus elliottii experiments }
$$

$$
\text { Lmin }=0.4178+\mathrm{D} * 0.0980 \text { for all Pinus patula experiments }
$$

The four coefficients are highly significant, and surprisingly similar. The relationship between the minimum average spacing and average tree size is assumed to be linear, at least up to the point when the tree size does not increase sufficiently, but mortality continues. It appears that, after reaching an average dbh of about $60 \mathrm{~cm}$, the trees start dying, not as a result of competitioninduced self-thinning, but possibly because of other factors, such as failing defence mechanisms and reduced ability to survive pathogen attacks.

Shvidenko et al. (2006) describe the development of the number of trees per ha and the average tree diameter for fully stocked Pinus sylvestris forests in the forest tundra and northern taiga ecoregions in the European part of Russia. These data show a linear relation between $\mathrm{L}$ and $\mathrm{D}$ up to the age of 200 years. For the CCT data of the two pine species, the relationships appears to be linear up to a mean diameter of about $60 \mathrm{~cm}$.

\section{Tree survival}

Survival functions (Equation 7) were fitted to different planting densities of the two pine species in each of the four CCT experiments listed in Additional file 3: Table S3. Figure 3 presents examples of the fitted functions involving Pinus elliotti with four different planting densities of the CCT experiments MacMac and Kwambonambi.

The parameter estimates of the 32 survival functions are presented in Additional file 4: Table S4. The scale (b) and shape (c) parameters of the Weibull distribution are 

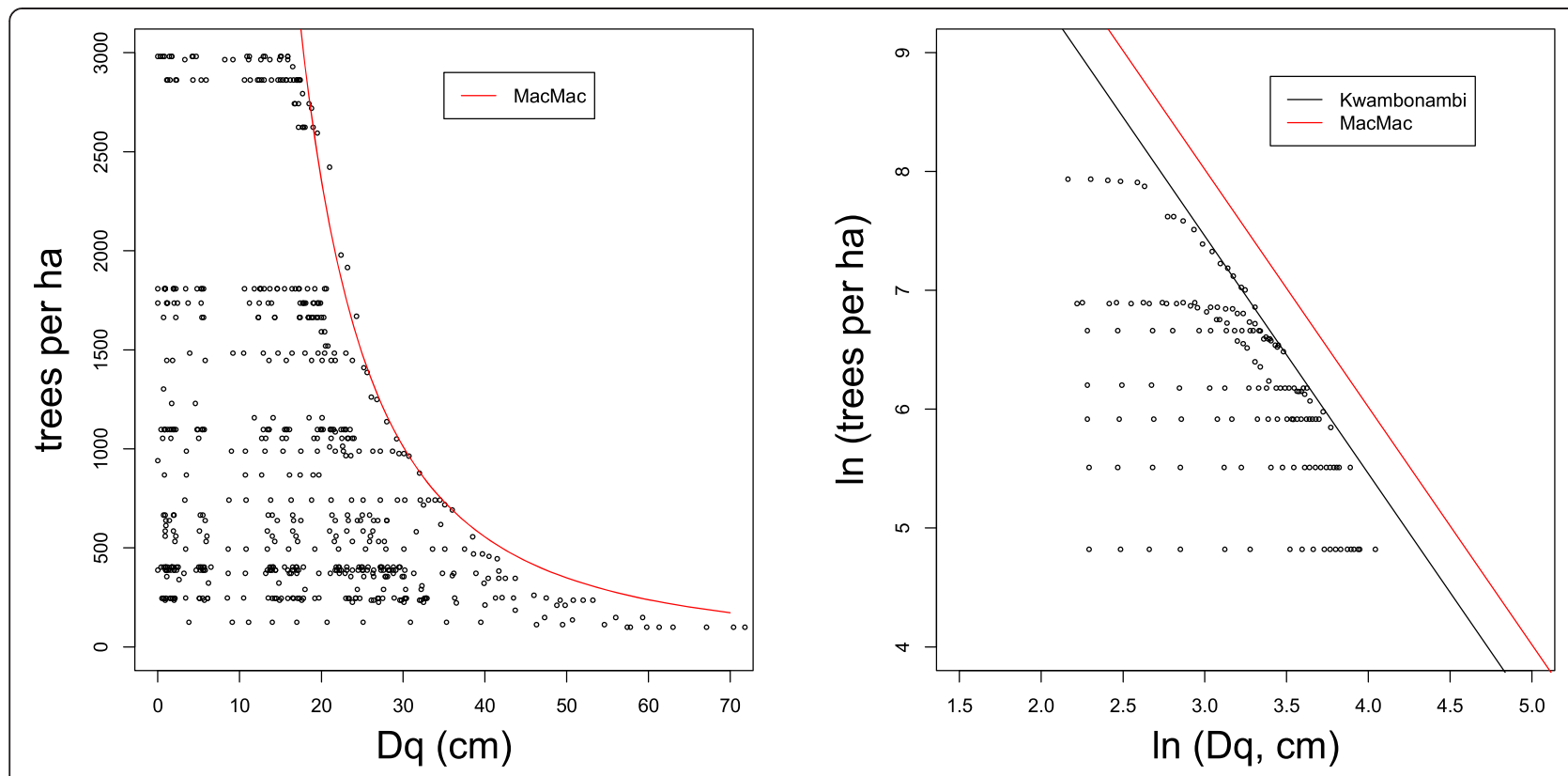

Figure 1 Limiting line fitted to Pinus elliottii MacMac using the 0.975 percentile data (left) and the same line for MacMac and Kwambonambi with the log transformed variables.

linear functions of the number of planted trees per ha and may be estimated using the following linear models:

$$
\begin{aligned}
& \ln (\mathrm{c})=\mathrm{AC}+\mathrm{BC} * \ln (\text { number of planted trees per ha }) \\
& \ln (\mathrm{b})=\mathrm{AB}+\mathrm{BB} * \ln (\text { number of planted trees per ha })
\end{aligned}
$$

The four parameters of these two equations are listed for each of the 8 experiments in the last two columns of
Additional file 4: Table S4. These results show that the Weibull function is suitable for estimating individual tree survival for both species and planting densities between 2965 and 741 trees per ha.

This relationship is potentially useful in that it permits estimating the lifetime distribution for a range of planting densities. The probability of tree survival and tree mortality is affected by the planting espacement and as expected,
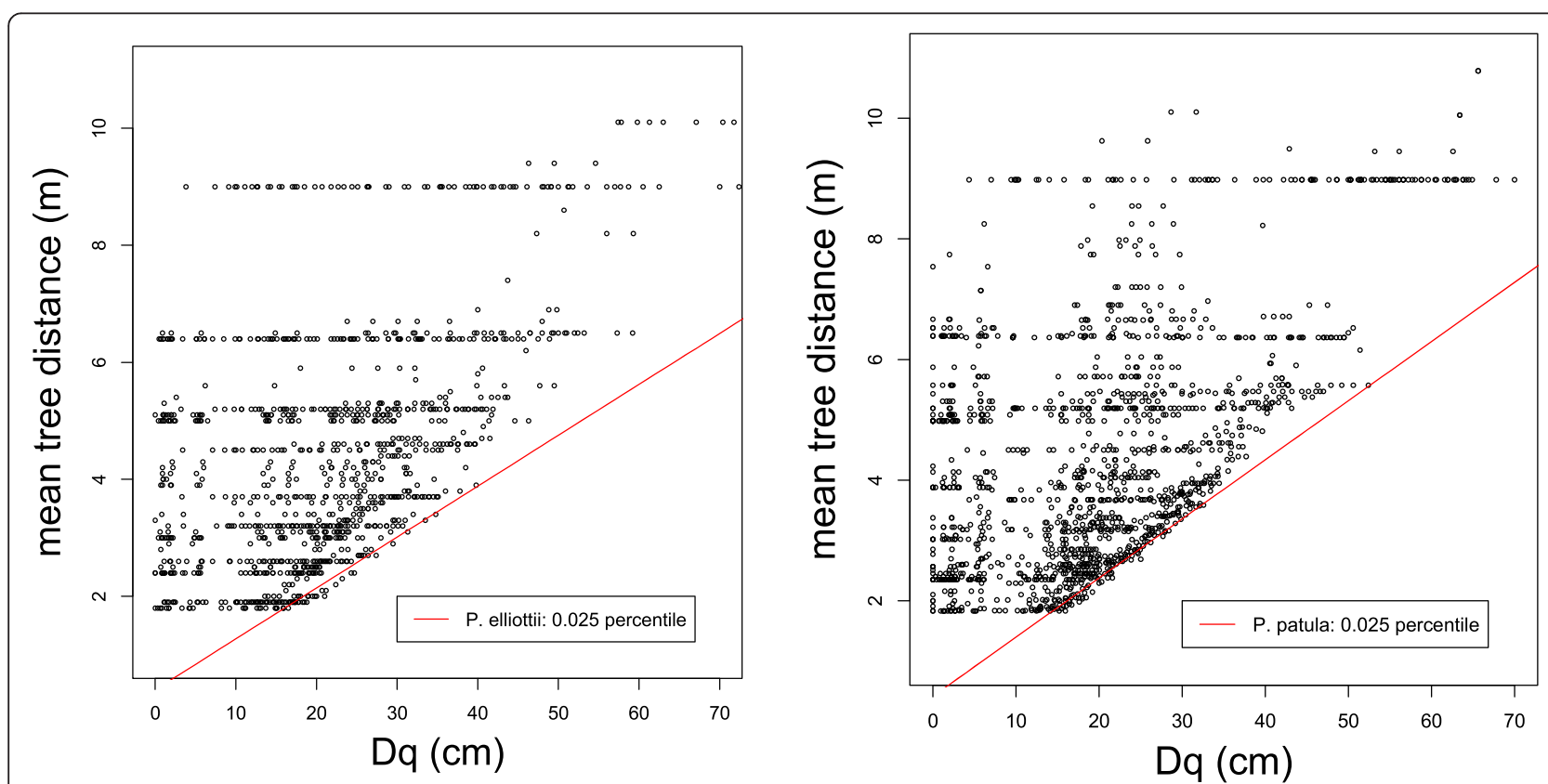

Figure 2 Estimates of maximum density with Nilson's Sparsity. Left: for all Pinus elliottii trials; right: for all Pinus patula trials, both using the 0.025 percentile values and the $R$ library quantreg. 


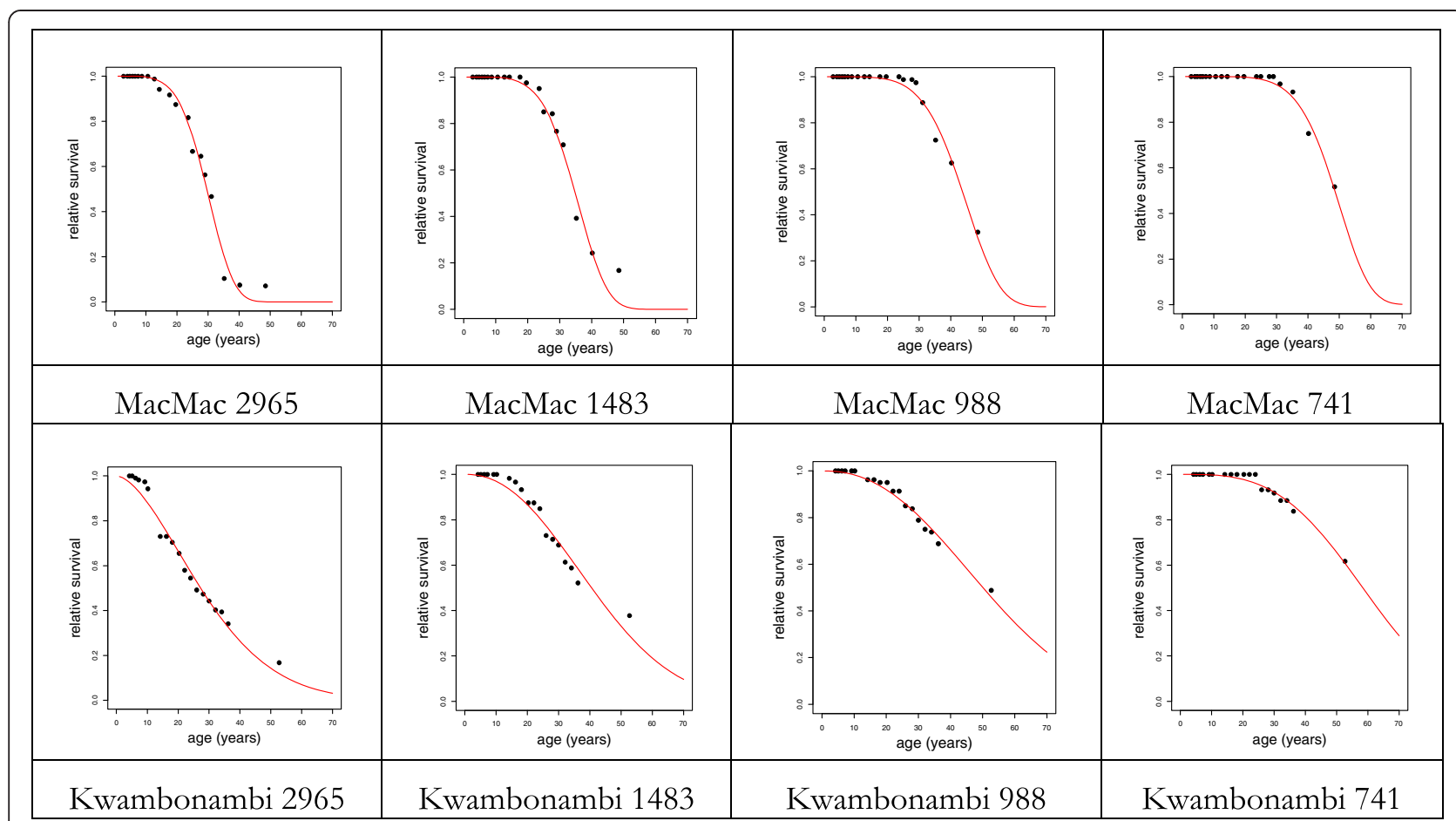

Figure 3 Examples of tree survival functions fitted to four different planting densities of the Pinus elliottii CCT experiments MacMac and Kwambonambi. The parameter estimates are listed in Additional file 4: Table S4.

the probability of tree survival is increasing with decreasing number of planted trees per unit area. The peaks of tree mortality occur earlier, and this effect is longer lasting, in the higher planting densities. These characteristic differences are notable for both species and the entire range of ages. It was also possible to relate the Weibull parameters to site index using the following linear equations with both Pinus patula and P. elliottii data combined:

$$
\begin{aligned}
& \mathrm{c}=-1.611+0.2336(\mathrm{SI} 2) \\
& \mathrm{b}=110.46-2.813(\mathrm{SI} 20)
\end{aligned}
$$

The slope coefficients were significant in both equations, but the intercept was only significant in equation (15). Interestingly, the response of the two species does not appear to be different. However, it must be pointed out again that the database is too limited to draw general conclusions about the relationship between site index and Weibull parameters.

\section{Discussion and conclusions}

The extensive South African spacing experiments, maintained for rather long periods of time, provide very important information for the scientific analysis of maximum forest density and tree survival. The "limiting line" approach presented in this study is an attempt to describe the relationship between average tree size and number of trees per unit area. Reineke proposed a slope constant of -1.605 which has been widely accepted and applied in many subsequent studies. Yoda's $3 / 2$ power line of ecology represents a similar attempt to explain self-thinning with a very simple model. Both models have been questioned by a number of authors, including Zeide $(1985,1987)$ and (Gadow 1986). This study has once again confirmed that a generalisation of the Reineke exponent cannot be substantiated by empirical observation, and that any model should be examined under a variety of specific conditions, before being labelled a "unified theory of ecology".

\section{Nilson's sparsity}

Nilson (2006; see also Hilmi 1957) argues that the most simple and logical relation is expected between variables of the same dimension, which is not the case in the Reineke model (Equation 1). For this reason, and because of its simpler form, Equation (3) was thought to be preferable when compared with Equation (1). A general discussion on the assumption of linearity of Nilson's sparsity is not possible, because the CCT material does not cover the seedling stage and stands older than about 60 years. The tables published by Shvidenko et al. (2006) for Russian Pinus sylvestris forests on site quality II show that Nilson's sparsity is linear up to the age of 180 years. However, the available material shows that the assumption of linearity cannot be confirmed for the Pinus patula CCT studies. Considering the culmination of diameter increment of 
Russian $P$. sylvestris and the much faster growing $P$. patula in South Africa one might expect that a deviation from linearity, should it signify a general, species independent pattern, could be induced at much higher ages in $P$. sylvestris. It is known that stem diameter scales well with crown extension and thus light competition and that these relations are very species specific, at least for conifers, which might affect the relationship.

\section{Development of density over age}

The maximum density of a planted forest is usually unknown because of the high cost to obtain empirical observations that permit a credible analysis of that elusive natural phenomenon. In addition to the observations about maximum density, the CCT experiments provide information about the development of forest density. The development of relative spacing, the average distance between the trees divided by the dominant height, is shown in Figure 4.

The minimum relative spacing (RS) in the Pinus elliottii experiment MacMac is 0.0752 , observed at age 24 . The minimum RS in the P. patula experiment MacMac is 0.095 , observed at age 18 . The maximum basal areas are $56.6 \mathrm{~m}^{2} /$ ha at age 28 for $P$. patula MacMac $83.6 \mathrm{~m}^{2} /$ ha at age 24 for P. elliottii MacMac.

\section{The nelder design}

Maintaining a series of large field plots over long periods of time is expensive. One attempt to reduce such high costs is the design proposed by Nelder (1962). The compact Nelder design consists of a number of spokes of an imaginary wheel with trees planted at different radial distances, at the intersection of circular arcs and linear spokes (Barry 2013). Parrot et al. (2012) discuss various aspects of the Nelder design which allows the effects of different planting densities to be examined in a single experiment. The experimental unit in a Nelder design is the individual tree and research usually involves to relating the available growing area of each tree to growth rates or tree architecture (Gaul and Stüber 1996; Mabvurira and Miina 2002; Aphalo and Rikala 2006). According to Affleck (2001) the analysis of Nelder experiments is problematic because the compact arrangement of trees may result in significant correlations among neighbouring variables. Hall (1994) notes that seedling survival is a primary concern when establishing Nelder plantings because a major drawback of the Nelder design is the sensitivity of the analysis to tree mortality (see also Stape and Binkley 2010).

The compact Nelder design, although having a cost advantage, only presents observations about the relationship between available growing space, tree growth and tree architecture. The Nelder wheel does not provide information about maximum density and the analysis is usually limited to the juvenile stage (Gaul and Stüber 1996). As mentioned before, data about the maximum density of planted forests are very scarce because the cost of maintaining a series of unthinned,

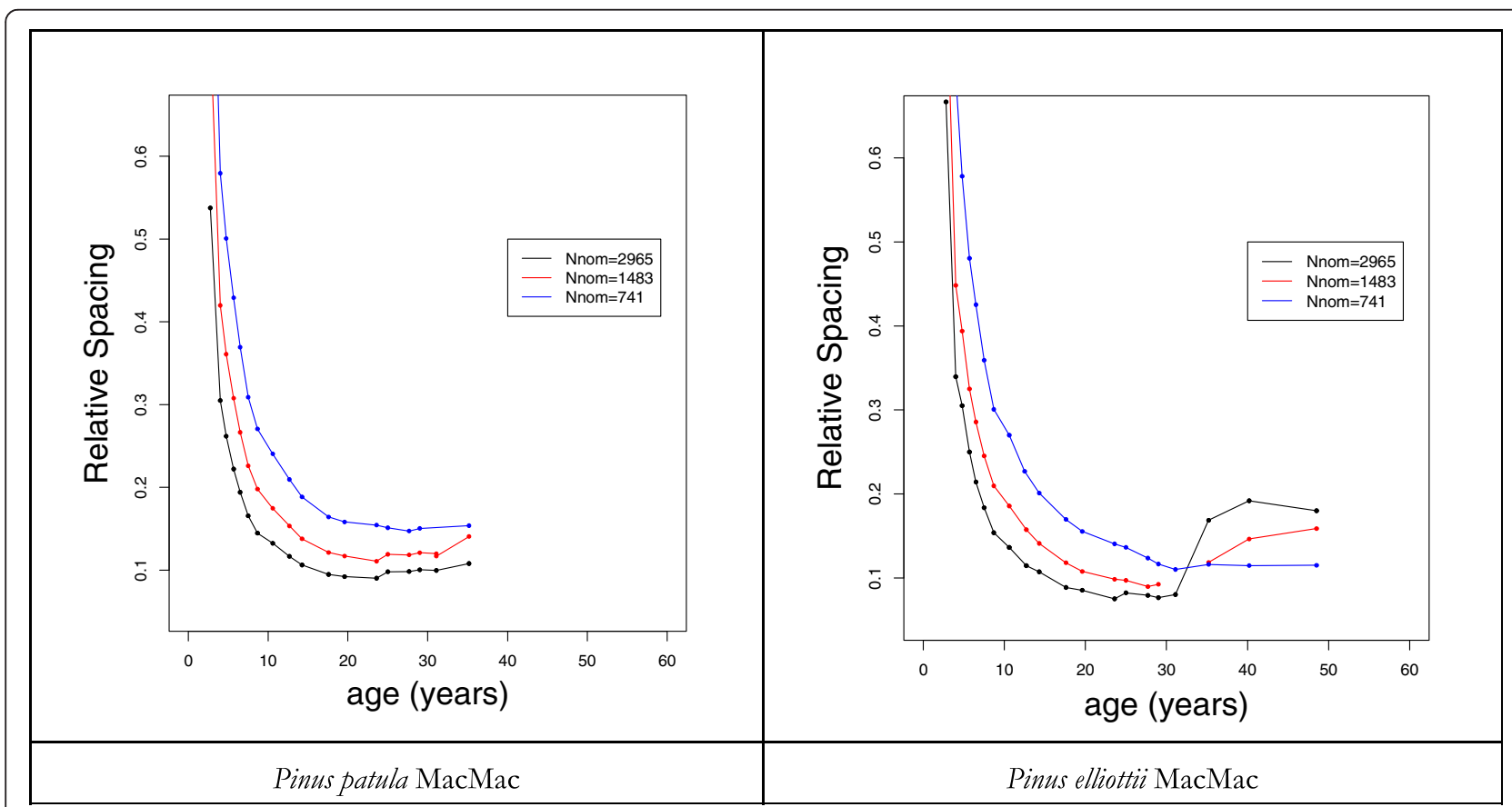

Figure 4 Development of relative spacing (the average distance between the trees divided by the dominant height) for two species and three different planting densities (2965, 1483 and 741 trees per ha). 
densely-stocked and sufficiently large field plots over long periods of time may be exorbitant. The CCT experiments represents, therefore, a valuable source of information for the analysis of maximum density and tree survival. Surprisingly few studies have used these unique datasets.

\section{Risk and uncertainty}

This contribution is part of a thematic series on risk and uncertainty. It is therefore appropriate to relate the results to the overall topic. The scientific analysis of risk and uncertainty in the context of natural hazards had its beginning at the turn of the $18^{\text {th }}$ century, when catastrophic events were no longer considered simple acts of destiny, but as relations of causes and effects (Weiss 2001). Plantation forest ecosystems have become an important strategic resource in a number of countries. Many industrial plantations are re-established after clearfelling and never thinned, especially those grown on short rotations and for maximum biomass, and their development resembles that of the unthinned CCT series. This study, therefore, contributes to a better understanding of tree survival and maximum density which are the key factors required for estimating risk and uncertainty. The risk of tree mortality is not constant, but varies with tree species, planting density, tree age and growing site. For estimating that risk, therefore, continuous long-term observation on different sites and with varying planting densities, as provided by the unthinned CCT series, are essential. Because of the particular risks involved in overaged plantations, such observational studies should be maintained as long as possible, preferably beyond the age of natural tree longevity.

\section{Additional files}

Additional file 1: Table S1. List of CCT experiments used in this study and their approximate geograpical location indicated by the trial number shown in the first column of the table on the left. MAT = mean annual temperature $\left({ }^{\circ} \mathrm{C}\right) ; \mathrm{MAP}=$ mean annual precipitation $(\mathrm{mm}) ; \mathrm{SI} 20=$ mean height of dominant trees at age 20; Soil texture: $\mathrm{Cl}=$ clay, $\mathrm{Lm}=$ loam, $\mathrm{Sa}=$ sand

Additional file 2: Table S2. Left: Trees per ha planted for the CCT unthinned pine series. Right: Map of the CCT spacing study at Nelshoogte. The colored plots represent the unthinned series. Each of the four replications of one planting espacement covers an area of 0.081 ha (after Gadow and Bredenkamp 1992).

Additional file 3: Table S3. Parameter estimates for the limiting line involving the entire dataset. All coefficients are highly significant. The graph on the right shows the relationship between the SI20 and the intercept of the limiting line for P. elliotti (circles) and P. patula (black dots).

Additional file 4: Table S4. Weibull scale (b) and shape (c) parameters for 32 survival functions fitted to four different planting densities of the eight CCT experiments.

\section{Competing interests}

The authors declare that they have no competing interests.

\section{Authors' contribution}

HK acquired and prepared the summary data. KGv did the data analysis and constructed the article. HK edited the final version of the ms. Both authors read and approved the final manuscript.

\section{Acknowledgements}

We wish to express our gratitude to all those who conceived and implemented the South African spacing experiments. Special thanks are due to the individuals who measured the trees and to the institutions, especially the former South African Forest Research Institute and its successors, who made these unique observations available for research.

\section{Author details}

${ }^{1}$ Department of Forest and Wood Science, University of Stellenbosch, Stellenbosch, South Africa. ${ }^{2}$ University of Göttingen, Göttingen, Germany. ${ }^{3}$ Mondi, South Africa Division, Hilton, South Africa.

Received: 7 August 2014 Accepted: 3 October 2014

Published online: 15 October 2014

\section{References}

Affleck DLR (2001) A Comparative Study of Spatial Analysis Methods for Forestry Nelder Experiments, MSc Thesis. University of British Columbia, p 70

Aphalo PJ, Rikala R (2006) Spacing of silver birch seedlings grown in containers of equal size affects their morphology and its variability. Tree Physiol 26 (9):1227-1237

Barry RP (2013) Nelder Plots. Encyclopedia of Environmetrics 4

Bredenkamp BV (1984) The CCT Concept In Spacing Research - A Review. In: Proceedings of the IUFRO Symposium On Site And Productivity Of Fast Growing Plantations. Pretoria and Pietermaritzburg, South Africa, 1984

Bredenkamp BV, Kotze H, Kassier H (2000) The Langepan CCT. A Guide To A Correlated Curve Trend Spacing Experiment in Eucalyptus grandis at Kwambonambi, Kwazulu-Natal. South African Forestry Company Limited, Pretoria, South Africa

Burgers TF (1976) Management Graphs derived from the Correlated Curve Trend (CCT) Projects, South African For Res Inst, Bulletin Nr. 54, Dept. Forestry, Pretoria, South Africa

Cox DR, Oakes D (1984) Analysis of Survival Data. Chapman \& Hall, London

Craib IJ (1939) Thinning, Pruning And Management Studies On The Main Exotic Conifers Grown in South Africa. Govt. Printer, Pretoria

Dickel M, Kotze H, Gadow KV, Zucchini W (2010) Growth and Survival of Eucalyptus grandis - a Study based on Modeling Lifetime Distributions. Int J Math Comput Forestry Nat Resour Sci 2(2):20-30, available online at http://mcfns.com/index.php/Journal/article/view/MCFNS.2-86

Drew TJ, Flewelling JW (1979) Stand density management: an alternative approach and its application to Douglas-fir plantations. For Sci 25:518-532

Gadow KV (1986) Observations on self-thinning in pine plantations. S Afr J Sci 82(7):364-368

Gadow KV (1987) Untersuchungen Zur Konstruktion Von Wuchsmodellen Für Schnellwüchsige Plantagenbaumarten. Universität München, Forstl. Forschungsberichte, Nr. 77, $147 \mathrm{~S}$

Gadow KV (2013) Messung und Modellforschung - Grundlagen der Forsteinrichtung (Measurement and Modeling Research - Basis for Forerst Design). Allgemeine Forst und Jagdzeitung 184(7/8):143-158

Gadow KV, Bredenkamp BV (1992) Forest Management. Academica Press, Pretoria

Gaul HT, Stüber V (1996) Der Eichen-Nelder-Verbandsversuch Göhrde. Forst und Holz 51:70-75

Gingrich SE (1967) Measuring and evaluating stocking and stand density in Upland hardwood forest in the Central States. For Sci 13:38-53

Grace J, Berninger F, Nagy L (2002) Impacts of climate change on the tree line. Ann Bot (London) 90(4):537-544

Greenberg JA, Dobrowski SZ, Vanderbilt VC (2009) Limitations on maximum tree density using hyperspatial remote sensing and environmental gradient analysis. Remote Sens Environ 113:94-101

Hall RB (1994) Use of the crown competition factor concept to select clones and spacings for short-rotation woody crops. Tree Physiol 14(7-8-9):899-909

Hilmi GF (1957) Theoretical Bio-Geo Physics Of Forest. -- AN SSSR. USSR, Moscow [In Russian]

Hynynen J (1993) Self-thinning Models for Even-aged Stands of Pinus sylvestris, Picea abies and Betula pendula. Scand J For Res 8:326-336 
Klein JP, Moeschberger ML (1997) Survival Analysis: Techniques For Censored And Truncated data. Springer, New York

Lowrance WW (1980) The nature of risk. In: Schwing RC, Albers WA (eds) Societal Risk Assessment. How Safe is Safe Enough? Plenum Press, New York

Luyssaert S, Schulze ED, Börner A, Knohl A, Hessenmöller D, Law BE, Ciais P, Grace J (2008) Oldgrowth forests as global carbon sinks. Nature 455:11, September 2008 (doi:10.1038/nature07276)

Mabvurira D, Miina J (2002) Individual-tree growth and mortality models for Eucalyptus grandis (Hill) Maiden plantations in Zimbabwe. For Ecol Manag 161(1-3):231-245

Marsh EK (1957) Some Preliminary Results From O'connor's Correlated Curve Trend (CCT) Experiments On Thinning And Espacements And Their Practical Significance. Commonwealth For. Conf., 1957. The Government Printer, Pretoria, South Africa

Nelder JA (1962) New kinds of systematic designs for spacing experiments, Biometrics 18:283-307

Nilson A (2006) Modeling Dependence Between The Number Of Trees And Mean Tree Diameter Of Stands, Stand Density And Stand Sparsity. In: Cieszewski CJ, Strub M (eds) Second International Conference on Forest Measurement and Quantitative Methods and Management \& the 2004 Southern Mensurationists Meeting 15-18 June 2004 Hot Springs, Arkansas USA. University of Georgia, Athens, USA

O'Connor AJ (1935) Forest Research with Special Reference to Planting Distances and Thinning. Govt. Printer, Pretoria

O'Connor AJ (1960) Thinning Research. J S Afr Forestry Assoc 34:65-88

Oliver CD, Larson BC (1996) Forest Stand Dynamics. Wiley, New York

Parrott D, Brinks J, Lhotka J (2012) Designing Nelder wheel plots for tree density experiments. New For 43(2):245-254

Reineke LH (1933) Perfecting a Stand Density Index for Even-Aged Forests. J Agric Res 46(7):627-638

Shvidenko AZ, Schepaschenko DG, Nilson S, Buluy YI (2006) Tables and Models of Growth and Productivity of Forests of Major Forests Forming Species of Northern Eurasia. Ministry of Natural Resources, Federal Agency of Forest Management, International Institute for Applied Systems Analysis, Vienna

Stape JL, Binkley 0 (2010) Insights from full-rotation Nelder spacing trials with Eucalyptus in Sao Paulo, Brazil. S For 72(2):91-98

Staupendahl K (2011) Modellierung der Überlebenswahrscheinlichkeit von Waldbeständen mithilfe der neu parametrisierten Weibull-Funktion [Modelling the survival probability of forest stands using the reparametrised Weibull function]. Forstarchiv (82):10-19 (in German, with English summary)

Staupendahl K, Zucchini W (2011) Schätzung von Überlebensfunktionen der Hauptbaumarten auf der Basis von Zeitreihendaten der Rheinland-Pfälzischen Waldzustandserhebung [Estimating survival functions for the main tree species based on time series data from the forest condition survey in Rheinland-Pfalz, Germany]. Allg Forst- Jagdztg 182(5/6 (in print)): (in German, with summaries in English and French

Van Laar A (1982) The response of Pinus radiata to initial spacing. S Afr For J 121:52-63

Weibull W (1951) A statistical distribution of wide applicability. J App Mech 18:293-297

Weiss G (2001) Administrating Risk - A Social Science Perspective On Natural Hazard Prevention Based On An Austrian Case Study. In: Gadow KV (ed) Risk Analysis in Forest Management. Vol 2 in the Book Series Managing Forest Ecosystems. Kluwer Academic Publishers, pp 171-200

Yoda K, Kira T, Ogawa H, Hozumi K (1963) Self-thinning in overcrowded pure stands under cultivated and natural conditions. J Biol Osaka City Univ 14:107-132

Zeide B (1985) Tolerance and Self Tolerance of Trees. For Ecol Manag 13:149-166 Zeide B (1987) Analysis of the 3/2 power law of self thinning. For Sci 33:517-537

Zeide B (2004) How to measure stand density. Trees 19:1-14

doi:10.1186/s40663-014-0021-4

Cite this article as: Gadow and Kotze: Tree survival and maximum density of planted forests - Observations from South African spacing studies. Forest Ecosystems 2014 1:21.

\section{Submit your manuscript to a SpringerOpen ${ }^{\circ}$ journal and benefit from:}

- Convenient online submission

- Rigorous peer review

- Immediate publication on acceptance

- Open access: articles freely available online

- High visibility within the field

- Retaining the copyright to your article

Submit your next manuscript at $\gg$ springeropen.com 